\title{
Estimation of Long-Run Inefficiency Levels: A Dynamic Frontier Approach
}

\author{
Seung C. Ahn*, David H. Good ${ }^{* *}$, Robin C. Sickles**** \\ *Arizona State University, Tempe, Arizona. \\ ** Indiana University, Bloomington, Indiana \\ **** Rice University, Houston, Texas
}

Keywords and Phrases: panel data; long-run inefficiency; frontier production function; generalized method of moments

JEL Classification: C23, D2

\begin{abstract}
Cornwell, Schmidt, and Sickles (1990) and Kumbhakar (1990), among others, developed stochastic frontier production models which allow firm specific inefficiency levels to change over time. These studies assumed arbitrary restrictions on the short-run dynamics of efficiency levels which have little theoretical justification. Further, the models are inappropriate for estimation of long-run efficiencies. We consider estimation of an alternative frontier model in which firmspecific technical inefficiency levels are autoregressive. This model is particularly useful to examine a potential dynamic link between technical innovations and production inefficiency levels. We apply our methodology to a panel of US airlines.
\end{abstract}




\section{Introduction}

Many previous panel data studies of technical efficiency estimate frontier functions and firm-specific inefficiency levels with a strong assumption that the inefficiency levels are time-invariant (see, for example, Schmidt and Sickles, 1984; Kumbhakar, 1987). These studies typically have relied on static reduced form models to describe production slack, providing little or no role for dynamics in explaining time-varying efficiency levels. While static reduced form models have been motivated from economic models of cost minimization, or profit maximization, they allow for only a limited explanation and, hence, a limited analysis, of the sources of production slack. This is especially true when the production slack changes over time. The shortcoming of such models is their inability to link measurable changes in technical inefficiency to a more sensible economic model which would allow for a structural interpretation of the determinants of absolute and relative efficiency levels.

Only a few previous studies have allowed for dynamics in panel data models of technical inefficiency. Examples are Cornwell, Schmidt and Sickles (1990), Kumbhakar (1990), Battese and Coelli (1992), Lee and Schmidt (1993) and Ahn, Lee and Schmidt (1995). While these studies propose flexible ways to estimate the temporal pattern of time-series variations in firms' inefficiency levels, they do so at the cost of imposing arbitrary restrictions on the dynamics. With the exception of Lee and Schmidt, these studies model technical inefficiency as a fixed function of time. Lee and Schmidt (1993) use a nonlinear model which allows for any arbitrary pattern of temporal change in technical inefficiency but with the restriction that the pattern is identical for all firms. Battese and Coelli (1992) model technical inefficiency as an exponential function of time. Cornwell, Schmidt and Sickles (1990) allow firm effects to vary over time but in quadratic form. Kumbhakar (1990) allows for an alternative specification, where technical inefficiency is an exponential function of quadratic time.

Although these previous studies may provide reasonable approximations for the 
dynamics of short-run technical inefficiency, they have two limitations. First, the models are inappropriate for the analysis of long-run dynamics on technical inefficiency. For example, in the Cornwell, Schmidt and Sickles (1990) specification, a firm's technical inefficiency increases or decreases infinitely with time, T. That is, technical inefficiencies do not converge. In Kumbhakar's model, technical inefficiency converges to a finite level as T grows, but this also means that in his model inefficiency varies little for large T. Second, the dynamic specifications of firms' inefficiencies proposed by these studies are arbitrary functional approximations with little theoretical or intuitive justifications.

The purpose of this paper is to study a dynamic panel data model which allows flexible and economically meaningful dynamics in a framework that also allows for the estimation of firms' long-run technical inefficiency levels. Specifically, we consider a model in which technical inefficiency levels are permitted to be serially correlated with potentially different patterns across firms. Our application of U.S. airlines during the regulatory transition from 1981 through 1992 illustrates several of the motivations for such a model. First, we do not anticipate that firms will immediately be able to adjust their input levels to optimal values, because many of the inputs, aircraft, crews and route structures are quasi-fixed. Short run efficiency levels may also vary for institutional reasons. Civil Aeronautics Board regulation of the airline industry was chartered with maintaining financial viability of the industry, despite the presence of sometimes substantial inefficiencies. One obvious source of such short-run variations in technical inefficiency is a firm's tardy adjustment of their inefficiency levels. Another possible source of the short-run variations is technical innovations in the industry. Technical innovations may affect both short-run and long-run efficiency levels. Specifically, in an industry which faces technical innovation over time, firms may adopt such innovations in a sluggish manner. This form of rigidity keeps firms from optimally choosing input levels in each period, because they are unable to adjust instantly. The assumption that firms may adopt continuous technical innovations in a sluggish manner leads to a dynamic panel data 
model. Estimating this model, we can identify and test for long-run differences in inefficiency.

Our empirical application to U.S. airlines during the deregulatory transition is an interesting one in this respect since Civil Aeronautics Board regulation was charged with promoting financial viability of firms despite large and widely varying levels of inefficiency. Our application illustrates what we believe to be the important generality of our model. Inefficiency levels may vary because of prior institutional regimes. Inefficiencies are slow to disappear because of the potentially large adjustment costs associated with network structure, union work rules and aircraft fleets.

A notable feature of our model is that it reduces to the traditional fixed effects model with auto correlated errors in which the fixed effects can be interpreted as each firm's long run technical efficiency. Still, since the traditional within estimator requires strict exogeneity of regressors, it is inappropriate for our model because our input variables are only weakly, not strictly, exogenous. Instead, we pose a choice between two alternative estimation procedures along with specification tests: Generalized method of moments or generalized least squares depending on whether the production frontier is stochastic or deterministic.

In section 2, we introduce our dynamic model and address related specification issues. Section 3 describes the estimation and specification-test procedures applied to the model. Section 4 provides a discussion of some institutional consideration of the airline industry, and provides a description of our data while section 5 describes our empirical results. Section 6 concludes.

\section{Specification}

In our basic model, we consider an industry, each firm of which produces a homogenous product with the following Cobb-Douglas production technology: 


$$
\mathrm{y}_{\mathrm{it}}^{\mathrm{F}}=\mathrm{X}_{\mathrm{it}} \beta+\alpha_{\mathrm{t}}^{\mathrm{F}}+\mathrm{v}_{\mathrm{it}}=\mathrm{X}_{\mathrm{it}} \beta+\beta_{0}+\gamma \mathrm{t}+\mathrm{v}_{\mathrm{it}} \text {, }
$$

where $\mathrm{y}_{\mathrm{it}}^{\mathrm{F}}=\ln \left(\mathrm{q}_{\mathrm{it}}^{\mathrm{F}}\right), \mathrm{X}_{\mathrm{it}}=\left[\ln \left(\mathrm{x}_{\mathrm{it}, 1}\right), \ldots, \ln \left(\mathrm{x}_{\mathrm{it}, \mathrm{k}}\right)\right]$ and $\beta=\left(\beta_{1}, \ldots, \beta_{\mathrm{k}}\right)^{\prime}$. Here, $\mathrm{i}=1, \ldots$, $\mathrm{N}$ indexes firms, $\mathrm{t}=1, \ldots, \mathrm{T}_{\mathrm{i}}$ denotes time, $\mathrm{q}_{\mathrm{it}}{ }^{\mathrm{F}}$ is the output level at the frontier, $\mathrm{x}_{\mathrm{it}, \mathrm{j}}$ is the level of input $\mathrm{j}$, the $\beta_{\mathrm{j}}$ are parameters describing the technology, $\alpha_{t}^{\mathrm{F}} \equiv \beta_{0}+\gamma \mathrm{t}$ denotes the time-varying component of technology which is common to every firm, and the $\mathrm{v}_{\mathrm{it}}$ is a random noise which is independently distributed over different $\mathrm{i}$ and $\mathrm{t}$ with zero mean. An alternative deterministic frontier can be obtained by dropping the $\mathrm{v}_{\mathrm{it}}$ from (1). Consistent with other stochastic production frontier studies, the input vectors in $X_{i t}$ are assumed to be strictly exogenous to the $v_{i t}$. We consider the Cobb-Douglas frontier purely for notational convenience. The model we derive below can be easily generalized to more general translog production functions though doing so is at the expense of global regularity and parameter parsimony.

While our econometric model can accommodate other, perhaps polynomial specifications of $\alpha_{t}^{\mathrm{F}}$ with respect to time, it is at the expense of our ability to identify each firm's long run efficiency level.

A firm's technical inefficiency measures its inability to make full usage of production capacity. Where present, the actual productivity level, which we denote by $\alpha_{i t}$, will be below $\alpha_{t}^{\mathrm{F}}$; that is, $\alpha_{\mathrm{it}}=\alpha_{\mathrm{t}}^{\mathrm{F}}-\mathrm{u}_{\mathrm{it}}$, where $\mathrm{u}_{\mathrm{it}}(\geq 0)$ is firm i's technical inefficiency level at time $t$. With this notation, we define the actual production by

$$
y_{i t}=X_{i t} \beta+\alpha_{i t}=X_{i t} \beta+\beta_{0}+\gamma t+v_{i t}-u_{i t} \cdot
$$

Specifications of the dynamic evolution of $\mathrm{u}_{\mathrm{it}}\left(\right.$ or $\left.\alpha_{\mathrm{it}}\right)$ are central to the choice of an appropriate estimation procedure for the frontier function and firms' long-run inefficiency levels. Our basic assumption is that each firm's inefficiency follows a simple AR(1) process:

$$
\mathrm{u}_{\mathrm{it}}=\left(1-\rho_{\mathrm{i}}\right) \mathrm{u}_{\mathrm{i}, \mathrm{t}-1}+\xi_{\mathrm{it}} ; \mathrm{E}\left(\xi_{\mathrm{it}} \mid \Omega_{\mathrm{i}, \mathrm{t}-1}\right)=\lambda_{\mathrm{i}} \geq 0
$$


where $\rho_{\mathrm{i}}$ measures firm i's ability to adjust its past-period inefficiency level $\left(0<\rho_{\mathrm{i}}\right.$ $\leq 1), \xi_{\mathrm{it}}$ is a nonnegative random noise, and $\Omega_{\mathrm{i}, \mathrm{t}-1}$ is the information set available to firm $i$ at the beginning of time $t$. Here, we assume that the $\xi_{i t}$ are independently distributed over different $i$ and $t$. The sizes of $\rho_{i}$ and $\lambda_{i}$ may differ across firms due to heterogeneity in average quality of a firm's management and workers. An implicit assumption behind (3) is that at the beginning of time period t, each firm learns about the level of the inefficiency $\left(\mathrm{u}_{\mathrm{i}, \mathrm{t}-\mathrm{l}}\right)$ it suffered during the last time period and remedies some part of the inefficiency $\left(\rho_{\mathrm{i}} \mathrm{u}_{\mathrm{i}, \mathrm{t}-\mathrm{I}}\right)$. Accordingly, a firm's current inefficiency depends on two factors; the unadjusted portion of the last-period inefficiency $\left(1-\rho_{\mathrm{i}}\right) \mathrm{u}_{\mathrm{i}, \mathrm{t}-1}$ and the new arrival of unexpected inefficiency sources $\xi_{\mathrm{it}}$. While we consider only this simple AR(1) specification, our estimation procedures discussed below can be easily extended to more general AR specifications.

In this paper, we only consider the cases with strictly positive $\rho_{\mathrm{i}}$ 's for economic and econometric reasons. When $\rho_{\mathrm{i}}=0$, specification (3) indicates that the inefficiency score $\mathrm{u}_{\mathrm{it}}$ becomes equal to the sum of all of the past positive inefficiency shocks $\xi_{\mathrm{it}}$. Accordingly, the inefficiency level of a firm with $\rho_{\mathrm{i}}=0$ should explode over time. Such firms can not continue for long in a competitive industry. Further, when $\rho_{\mathrm{i}}=0$, the firms' actual output levels will be nonstationary. The econometric methods we introduce later are only appropriate for the analysis of stationary or trend-stationary data, but not for the data with stochastic trends. Accordingly, our econometric methods do not provide for modeling or testing persistent inefficiency shocks. A more general approach that applies to both stationary or nonstationary input and output data should be an useful extension to this research.

While our AR specification might appear to be naive, it provides two important features: First, it allows the identification of long-run average inefficiency levels $\lambda_{\mathrm{i}} / \rho_{\mathrm{i}}$. Furthermore, our specification seems well motivated economically. Consider a firm which is currently operating efficiently. Now, some shock is introduced into the environment. Such a shock may be the availability of new technology, the removal of regulations, or changes in the behavior of competitors. In equilibrium, firms will 
react to these changes and again be efficient.

In the short run, though, because the capital inputs are quasi-fixed and union contracts already have been negotiated, the inefficiencies associated with this one time shock will be persistent. Efficient management will be able to remove these inefficiencies and reach the new equilibrium more quickly than inefficient management. Quickly responding management is characterized by $\rho_{\mathrm{i}}$ close to 1 .

In the panel data frontier models, inefficiency is often assumed to be timeinvariant for a particular firm. We generalize this idea by allowing inefficiency to be time varying with a partial adjustment process. To see this, let a random variable $\eta_{\text {it }}$ $(\geq 0)$ denote a firms time-varying inefficiency score. We assume $E\left(\eta_{\mathrm{it}} \mid \Omega_{\mathrm{it}}\right)=\kappa_{\mathrm{i}} \geq 0$. With the $\eta_{\mathrm{it}}$, we define $\alpha_{\mathrm{it}}^{*}=\alpha_{\mathrm{t}}^{\mathrm{F}}-\eta_{\mathrm{it}}=\beta_{0}+\gamma \mathrm{t}-\eta_{\mathrm{it}}$, where $\alpha_{\mathrm{it}}^{*}$ is firm i's productivity level which could be achieved if the firm would adopt technology innovations timely. Suppose now that firms adjust their production technology only slowly over time. Specifically, we assume that technical innovations introduced at the beginning of time $\mathrm{t}$ are only partially adopted; that is, $\alpha_{\mathrm{it}}=\left(1-\rho_{\mathrm{i}}\right) \alpha_{\mathrm{i}, \mathrm{t}-1}+\rho_{\mathrm{i}} \alpha_{\mathrm{it}}^{*}$. Then, the technical inefficiency $u_{i t}=\alpha_{t}^{F}-\alpha_{i t}$ must be correlated with its lagged levels, because we have

$$
u_{i t}=\left(1-\rho_{i}\right) u_{i, t-1}+\left(1-\rho_{i}\right) \gamma+\rho_{i} \eta_{i t}
$$

which reduces to specification (3) if we denote $\xi_{\mathrm{it}}=\left(1-\rho_{\mathrm{i}}\right) \gamma+\rho_{\mathrm{i}} \eta_{\mathrm{it}}$ and $\lambda_{\mathrm{i}}=\left(1-\rho_{\mathrm{i}}\right) \gamma+\rho_{\mathrm{i}} \kappa_{\mathrm{i}}$. Accordingly, the long-run average technical inefficiency level of firm i equals

$$
\mathrm{u}_{\mathrm{i}}^{\mathrm{LR}} \equiv \frac{\lambda_{\mathrm{i}}}{\rho_{\mathrm{i}}}=\kappa_{\mathrm{i}}+\frac{\left(1-\rho_{\mathrm{i}}\right) \gamma}{\rho_{\mathrm{i}}}
$$

which is finite unless $\rho_{i}=0$. The first component of $u_{i}^{L R}, \kappa_{i}$, measures the long-run inefficiency due to firm i's poor management. The second component $\left(1-\rho_{\mathrm{i}}\right) \gamma / \rho_{\mathrm{i}}$ captures the long-run efficiency loss due to the firm's sluggish adoption of technical innovations, which is negatively related with the adjustment speed $\rho_{\mathrm{i}}$. We note that the result (5) crucially depends on our assumption of linear trend, $\alpha_{t}^{\mathrm{F}}=\beta_{0}+\gamma \mathrm{t}$. When the industry productivity grows following a higher-order polynomial, the long-run 
inefficiency $u_{i}^{L R}$ should depend on time.

Our AR assumption on dynamics of $\mathrm{u}_{\mathrm{it}}$ are consistent with the production function of usual fixed effects form but with autocorrelated errors. To see this, define the short-run deviation of technical inefficiency from the long-run level $u_{i}^{L R}$ $\equiv \lambda_{\mathrm{i}} / \rho_{\mathrm{i}}$ by $\mathrm{u}_{\mathrm{it}}^{\mathrm{d}}=\mathrm{u}_{\mathrm{it}}-\mathrm{u}_{\mathrm{i}}^{\mathrm{LR}}$, With this notation and specification (3), we can rewrite the production function (2) as

$$
y_{i t}=X_{i t} \beta+\gamma t+\left(\beta_{o}-u_{i}^{L R}\right)-\varepsilon_{i t},
$$

where $\varepsilon_{\mathrm{it}}=\mathrm{u}_{\mathrm{it}}^{\mathrm{d}}-\mathrm{v}_{\mathrm{it}}$ and $\mathrm{u}_{\mathrm{it}}^{\mathrm{d}}=\left(1-\rho_{\mathrm{i}}\right) \mathrm{u}_{\mathrm{i}, \mathrm{t}-1}^{\mathrm{d}}+\left(\xi_{\mathrm{it}}-\lambda_{\mathrm{i}}\right)$. The error term $\varepsilon_{\mathrm{it}}$ in (6) will be autocorrelated unless $\rho_{\mathrm{i}}=1$.

The conventional within estimation procedure, which is equivalent to the least squares with dummy variables for each individual firms, might be used to consistently estimate the production function (6) if the input variables in $\mathrm{X}_{\mathrm{it}}$ were weakly exogenous to $\varepsilon_{\mathrm{it}}$. However, this condition could be violated even if firms are assumed to maximize expected profits as in Zellner, Kmenta and Drèze (1966). To illustrate this point, suppose that each firm is rational and determines its input levels at the beginning of each production time period to maximize its conditional expectation of profits $\left(\pi_{\mathrm{it}}\right)$ given the information set $\Omega_{\mathrm{it}}$; that is, firm i maximizes $\mathrm{E}\left(\pi_{\mathrm{it}} \mid \Omega_{\mathrm{it}}\right)$ with respect to the input vector $\mathrm{X}_{\mathrm{it}}$ given output and input prices. If a firm can observe its previous-period inefficiency level $\left(\mathrm{u}_{\mathrm{i}, \mathrm{t}-1}\right)$ at the beginning of time $\mathrm{t}$ as we assume for specification (3), the firm's input usages at time t must be correlated with $u_{\mathrm{it}}^{\mathrm{d}}$. For expository convenience, we assume that all future output and input prices are known. This assumption can be easily relaxed (Zellner, Kmenta and Drèze, 1966). Thus, $X_{i t}$ must be correlated with $\varepsilon_{i t}$ since the latter is a function of $u_{i t}^{d}$ which is serially correlated.

As a treatment of the problem, we may transform (6) into a nonlinear dynamic function:

$$
y_{i t}=X_{i t} \beta+\left(1-\rho_{i}\right) y_{i, t-1}+X_{i, t-1}\left[-\left(1-\rho_{i}\right) \beta\right]+\rho_{i} \gamma t+\rho_{i} \delta_{i}-e_{i t},
$$


where $\delta_{\mathrm{i}}=\beta_{0}-\mathrm{u}_{\mathrm{it}}^{\mathrm{d}}+\left(1-\rho_{\mathrm{i}}\right) \gamma / \rho_{\mathrm{i}}$ and $\mathrm{e}_{\mathrm{it}}=\left(\xi_{\mathrm{it}}-\lambda_{\mathrm{i}}\right)-\left[\mathrm{v}_{\mathrm{it}}-\left(1-\rho_{\mathrm{i}}\right) \mathrm{v}_{\mathrm{i}, \mathrm{t}-1}\right]$. This model can be identified even if we replace our linear time trend specification for $\alpha_{t}{ }^{F}$ by time dummy variables. When we use time effects $g_{t}$ instead of linear time trend, $\rho_{i} \gamma t+\rho_{i} \delta_{i}$ in (7) is replaced by $g_{t}-\left(1-\rho_{i}\right) g_{t-1}+\rho_{i} \varphi_{i}$, where $\varphi_{i}=\beta_{0}-u_{i}^{L R}$. Thus, the parameters $g_{t}$, $\rho_{\mathrm{i}}$ and $\varphi_{\mathrm{i}}$ are identified using time and individual dummy variables with the normalization $\mathrm{g}_{1}=0$, if both $\mathrm{T}$ and $\mathrm{N}$ are large. However, this time-dummy variable specification is inappropriate for data with small $\mathrm{N}$. This is so because the model suffers from incidental parameter problems when $\mathrm{N}$ is small compared to $\mathrm{T}$ (too many time-specific parameters compared to cross-section units $)^{1}$. Note that if $\rho_{\mathrm{i}}=$ 1 for all $i$, that is, all firms can promptly adjust their inefficiencies, model (7) reduces to the usual fixed-effects model with a linear time trend. Note also that if the frontier production function is deterministic (e.g, $\mathrm{e}_{\mathrm{it}}=\xi_{\mathrm{it}}-\lambda_{\mathrm{i}}$ ), all the regressors in (7) are weakly exogenous. Thus, under the same assumption, model (7) can be consistently estimated by nonlinear generalized least squares (NLGLS) incorporating the potential heteroskedasticity in $\xi_{\mathrm{it}}^{\mathrm{d}}$. In contrast, under our stochastic frontier assumption, $\mathrm{e}_{\mathrm{it}}$ is $\operatorname{MA}(1)^{2}$ and $y_{\mathrm{i},-1-1}$ is no longer weakly exogenous, so that NLGLS lead to biased estimates. Because of this problem, we need to use generalized methods of moments (GMM) to estimate the model (7). Detailed estimation procedures are discussed in section 3 .

\footnotetext{
${ }^{1} \mathrm{~A}$ referee raised an interesting identification issue for the cases in which the industry productivity $\alpha_{t}^{\mathrm{F}}$ follows a general autoregressive process in addition to time trends. The long-run inefficiency $\mathrm{u}_{\mathrm{i}}^{\mathrm{LR}}$ can be identified, even if $\alpha_{\mathrm{t}}^{\mathrm{F}}$ follows an autoregressive process. However, the adjustment speeds $\rho_{\mathrm{i}}$ are identified only if they are heteroskedastic. To demonstrate this, consider a simple model without input and time trends: $y_{i t}=\alpha_{t}^{F}+v_{i t}-u_{i t}$, where $\alpha_{t}^{F}=\pi \alpha_{t,-1}^{F}+h_{t}$. Assume that $h_{t}$ independently distributed over time with zero mean. For this model, we can easily show that

$$
\begin{aligned}
\mathrm{y}_{\mathrm{it}}-\left(1-\rho_{\mathrm{i}}+\pi\right) \mathrm{y}_{\mathrm{i}, \mathrm{t}-1} & +\pi\left(1-\rho_{\mathrm{i}}\right) \mathrm{y}_{\mathrm{i}, \mathrm{-}-2}+\rho_{\mathrm{i}}(1-\pi) \mathrm{u}_{\mathrm{i}}^{\mathrm{LR}} \\
& =\left[\mathrm{h}_{\mathrm{t}}-\left(1-\rho_{\mathrm{i}}\right) \mathrm{h}_{\mathrm{t}-1}\right]-\left[\left(\xi_{\mathrm{it}}-\lambda_{\mathrm{i}}\right)-\pi\left(\xi_{\mathrm{i}, \mathrm{t}-1}-\lambda_{\mathrm{i}}\right)\right]+\left[\mathrm{v}_{\mathrm{it}}-\left(1-\rho_{\mathrm{i}}+\pi\right) \mathrm{v}_{\mathrm{i}, \mathrm{t}-1}+\pi\left(1-\rho_{\mathrm{i}}\right) \mathrm{v}_{\mathrm{i}, \mathrm{t}-2}\right] .
\end{aligned}
$$

Clearly, the parameters $\left(1-\rho_{\mathrm{i}}\right), \pi$ and $\mathrm{u}_{\mathrm{i}}^{\mathrm{LR}}=\lambda_{\mathrm{i}} / \rho_{\mathrm{i}}$ are identified and can be estimated by GMM using $\mathrm{y}_{\mathrm{i}, \mathrm{t}}$ ${ }_{3}, \mathrm{y}_{\mathrm{i}, t-4}, \ldots$ as instruments. However, when $\rho_{\mathrm{i}}=\rho$ for all $\mathrm{i},(1-\rho)$ and $\pi$ are interchangeable so that they cannot be identified. These results also apply to usual production functions including both inputs and time trends.

${ }^{2}$ Note that the sum of a MA(1) process and white noise is also MA(1). See Hamilton (1994, pp. 102-105).
} 
In model (7), the number of parameters to be estimated grows with the number of firms $(\mathrm{N})$ present in data. Accordingly, it could be computationally burdensome, if not intractable, to estimate the model using data with large N. A more parsimoniously parameterized model would be desirable in practice. Such a model can be obtained if we can assume that the $\rho_{\mathrm{i}}$ (adjustment speeds) are the same for all i. Under this assumption, model (7) reduces to a simple dynamic panel data model in which all coefficients of regressors are assumed to be the same over different $i$. Studies regarding estimation of dynamic panel data models of this type are exhaustive in the literature, and a number of convenient GMM procedures are available, especially for data with large $\mathrm{N}$ and small $\mathrm{T}=\max _{\mathrm{i}}\left\{\mathrm{T}_{\mathrm{i}}\right\}$ (see, for example, Anderson and Hsiao, 1981; Arellano and Bond, 1991; and Ahn and Schmidt, 1995, 1997). ${ }^{3}$

In spirit, this homogeneity assumption on the $\rho_{\mathrm{i}}$ is akin to the assumption implicit in Lee and Schmidt (1993) that the pattern of temporal change in technical inefficiency is identical for all firms. While this restriction could considerably simplify necessary estimation procedures, estimates obtained with this restriction could be severely biased if the $\rho_{\mathrm{i}}$ are in fact different for each firm (see Pesaran and Smith, 1995). Therefore, the use of the restricted model should accompany appropriate specification tests discussed in section 3.

A possible criticism to our $\operatorname{AR}(1)$ assumption on firms' inefficiencies is that it is observably equivalent to an alternative $\operatorname{AR}(1)$ assumption imposed on the stochastic components of the frontier $\mathrm{v}_{\mathrm{it}}$ : That is, an alternative assumption that $\mathrm{u}_{\mathrm{it}}=$ $\mathrm{u}_{\mathrm{i}}^{\mathrm{LR}}$ for any $\mathrm{t}$ and $\mathrm{v}_{\mathrm{it}}=\left(1-\rho_{\mathrm{i}}\right) \mathrm{v}_{\mathrm{i}, \mathrm{t}-\mathrm{t}}+\mathrm{h}_{\mathrm{it}}$ also leads to the production function specified in (6). Our response to this possible criticism is two-fold. Firstly, whichever assumption is correct, firms' long-run average inefficiencies can be recovered from any consistent estimates of the parameters of (7). Secondly, it is possible to test for

\footnotetext{
${ }^{3}$ Our empirical study does not use the estimation procedures suggested by these studies. Their methods are inappropriate for our data which contain a large number of time-series observations on a relatively small number of cross-sectional firms.
} 
the alternative AR assumption against ours. In the stochastic frontier literature, the $\mathrm{v}_{\mathrm{it}}$ are nothing but "statistical noise" (See Schmidt, 1984, p. 304); that is, the $\mathrm{v}_{\mathrm{it}}$ are unexplainable error components which should not be systematically related with firms' input or output decisions. Thus, a firm's input decisions $\mathrm{X}_{\mathrm{it}}$ should be strictly exogenous to the $\mathrm{v}_{\mathrm{it}}$; all leads and lags of $\mathrm{X}_{\mathrm{it}}$ are uncorrelated with $\mathrm{v}_{\mathrm{it}}$. That is, $\mathrm{X}_{\mathrm{i}, \mathrm{t}-1}$ and $\mathrm{X}_{\mathrm{it}}$ should be uncorrelated with $\varepsilon_{\mathrm{it}}$ in (6), since $\varepsilon_{\mathrm{it}}$ simply equals $\mathrm{v}_{\mathrm{it}}$. In contrast, our assumption (3) implies that all the lagged values of $\mathrm{X}_{\mathrm{it}}$ are correlated with $\varepsilon_{\mathrm{it}}$ by the same reason as $X_{i t}$ is not weakly exogenous in (6). In short, a test for exogeneity of $X_{i t}$ and $X_{i, t-1}$ in (6) enables us to determine which of the $u_{i t}$ and $v_{i t}$ are autocorrelated. Following Ahn (1997), we can derive a convenient statistic for testing exogeneity of both $\mathrm{X}_{\mathrm{it}}$ and $\mathrm{X}_{\mathrm{i}, \mathrm{t}-\mathrm{t}}$ : We first estimate the model (6) by OLS including $\mathrm{X}_{\mathrm{i}, \mathrm{-}-\mathrm{l}}$ as additional regressors, and then conduct a Wald test for the significance of $\mathrm{X}_{\mathrm{i}, \mathrm{t}-\mathrm{1}}$. Intuitively, this test makes sense, because $\mathrm{X}_{\mathrm{i}, \mathrm{t}-1}$ should not explain $\mathrm{y}_{\mathrm{it}}$ if the $\mathrm{v}_{\mathrm{it}}$, not the $\mathrm{u}_{\mathrm{it}}$, are autocorrelated. ${ }^{4}$

\section{Estimation and Specification Tests}

We estimate and test for our dynamic model (7) using the generalized methods of moments (GMM) estimator which is outlined below. Define

$$
\mathrm{Z}_{\mathrm{it}}=\left[\mathrm{X}_{\mathrm{it}}, \mathrm{d}_{\mathrm{i}} \otimes\left(\mathrm{y}_{\mathrm{i}, \mathrm{t}-1}, \mathrm{X}_{\mathrm{i}, \mathrm{t}-1}, \mathrm{t}, 1\right)\right],
$$

where $d_{i}$ is the $1 \times N$ vector of dummy variables for individual firms. Define $y_{i}=$ $\left(\mathrm{y}_{\mathrm{i} 1}, \ldots, \mathrm{y}_{\mathrm{i}, \mathrm{Ti}}\right)^{\prime}$; and $\mathrm{X}_{\mathrm{i}}, \mathrm{Z}_{\mathrm{i}}$ and $\mathrm{e}_{\mathrm{i}}$ are similarly defined. For model (7), we denote the parameters of interest by $\theta=\left(\beta^{\prime}, \delta_{1}, \rho_{1}, \ldots, \delta_{N}, \rho_{N}\right)^{\prime}, \pi_{\mathrm{i}}=\left(\beta^{\prime}, 1-\rho_{\mathrm{i}},-\left(1-\rho_{\mathrm{i}}\right) \beta^{\prime}, \rho_{\mathrm{i}} \gamma, \rho_{\mathrm{i}} \delta_{\mathrm{i}}\right)^{\prime}$ and $\pi(\theta) \equiv\left(\pi_{1}{ }^{\prime}, \ldots, \pi_{\mathrm{N}}{ }^{\prime}\right)^{\prime}$. For the model with the restrictions $\rho_{\mathrm{i}}=\rho$, we denote $\theta=$

\footnotetext{
${ }^{4}$ Theorem 1 of Ahn (1997) implies that this Wald test is numerically identical to a Hansen test (1982) for the exogeneity of all the regressors in (6) and $X_{i, t-1}$. For the Wald test, we need a heteroskedasticity-and/or-autocorrelation-robust covariance matrix for the OLS estimates. This covariance matrix can be estimated by a method introduced in section 3 .
} 
$\left(\beta^{\prime}, \rho, \delta_{1}, \ldots, \delta_{\mathrm{N}}\right)^{\prime}$ and $\pi_{\mathrm{i}}=\left(\beta^{\prime}, 1-\rho,-(1-\rho) \beta^{\prime}, \rho \gamma, \rho \delta_{\mathrm{i}}\right)^{\prime}$. With this notation, model (7) can be written as

$$
\mathrm{y}_{\mathrm{i}}=\mathrm{Z}_{\mathrm{i}} \pi(\theta)-\mathrm{e}_{\mathrm{i}} .
$$

We have discussed in the previous section, the lagged dependent variable $\mathrm{y}_{\mathrm{i}, \mathrm{t}-1}$, which is a component of $Z_{i}$, is not weakly exogenous under the stochastic frontier assumption. Accordingly, consistent estimation of model (9) requires use of instrumental variables which are uncorrelated with the error vector $\mathrm{e}_{\mathrm{i}}$. Possible instruments are two-period (or more) lagged output levels, current and lagged input levels, time $(\mathrm{t})$, dummy variables $\left(\mathrm{d}_{\mathrm{i}}\right)$ for each firms. Let $\mathrm{W}_{\mathrm{it}}$ denote a set of such instruments; and let $\mathrm{W}_{\mathrm{i}}=\left[\mathrm{W}_{\mathrm{i} 1}{ }^{\prime}, \ldots, \mathrm{W}_{\mathrm{i}, \mathrm{Ti}}{ }^{\prime}\right]^{\prime}$. Define $\mathrm{f}_{\mathrm{i}}(\theta)=\mathrm{W}_{\mathrm{i}}{ }^{\prime}\left(\mathrm{y}_{\mathrm{i}}-\mathrm{Z}_{\mathrm{i}} \pi(\theta)\right)$ for each $\mathrm{i}$; and $\mathrm{m}(\theta)=\Sigma_{\mathrm{i}} \mathrm{f}_{\mathrm{i}}(\theta)$. If the instruments $\mathrm{W}_{\mathrm{i}}$ are legitimate, it must be the case that $\mathrm{E}[\mathrm{m}(\theta)]=0$. Under this condition and other standard GMM assumptions, we have

$$
\frac{1}{\sqrt{\sum_{\mathrm{i}} \mathrm{T}_{\mathrm{i}}}} \mathrm{m}(\theta) \stackrel{\mathrm{d}}{\rightarrow} \mathrm{N}(0, \Lambda)
$$

as $\Sigma_{\mathrm{i}} \mathrm{T}_{\mathrm{i}} \rightarrow \infty$. This result implies that the optimal GMM estimator of $\theta, \hat{\theta}_{\mathrm{GMM}}$, is obtained by minimizing

$$
\mathrm{J}(\theta)=\frac{1}{\Sigma_{\mathrm{i}} \mathrm{T}_{\mathrm{i}}} \mathrm{m}(\theta)^{\prime} \Lambda^{-1} \mathrm{~m}(\theta) .
$$

In practice, $\Lambda$ must be estimated to construct the criterion function $J(\theta)$. However, when each $\mathrm{T}_{\mathrm{i}}$ is large, it is straightforward to show that $\Lambda=\sum_{\mathrm{i}} \mathrm{r}_{\mathrm{i}} \Omega_{\mathrm{i}}$, where $\Omega_{\mathrm{i}}$ is the asymptotic covariance of $\sqrt{\mathrm{T}_{\mathrm{i}}} \mathrm{f}_{\mathrm{i}}(\theta)$ and $\mathrm{r}_{\mathrm{i}}=\lim _{\Sigma_{\mathrm{i}} \mathrm{T}_{\mathrm{i}} \rightarrow \infty} \mathrm{T}_{\mathrm{i}} / \Sigma_{\mathrm{i}} \mathrm{T}_{\mathrm{i}}{ }^{5}$. This result implies that a simple consistent estimate of $\Lambda$ can be obtained by $\hat{\Lambda}=\Sigma_{i}\left(T_{i} / \Sigma_{i} T_{i}\right) \hat{\Omega}_{i}$, where $\hat{\Omega}_{\mathrm{i}}$ is a consistent estimate of $\Omega_{\mathrm{i}}$. We can estimate $\Omega_{\mathrm{i}}$ by applying the Newey

\footnotetext{
${ }^{5}$ It is important to note that this result is obtained only if the error vector $e_{i}$ in (9) are cross-sectionally uncorrelated. This condition is violated if the error vector $\mathrm{e}_{\mathrm{i}}$ includes any random error common to all individual firms as in footnote 8 . For such cases, the covariance matrix $\Lambda$ depends on the crosssectional correlations among the $\mathrm{e}_{\mathrm{i}}$.
} 
and West (1987) method to each $\mathrm{f}_{\mathrm{i}}(\theta)$ evaluated at an initial consistent estimator of $\theta .{ }^{6}$ In our empirical study, we obtain the initial consistent estimator by nonlinear 2SLS using instruments $\mathrm{W}_{\mathrm{i}}$.

Once $\hat{\Omega}_{\mathrm{i}}$ is computed, the legitimacy of instruments and our stochastic frontier specification can be jointly tested with the J-statistic, J $\left(\hat{\theta}_{\mathrm{GMM}}\right)$. We also use an exogeneity test method which tests for weak exogeneity of the two-period lagged dependant variable $\left(\mathrm{y}_{\mathrm{i},-2}\right)$, which is constructed following Newey (1985b, p. 243). In our model, technical inefficiency is assumed to be AR(1). If inefficiency follows an autoregressive process of higher order, any lagged output levels are no longer weakly exogenous. While the J-test has power to detect such possible misspecification, the exogeneity test may have better power properties (see Newey, 1985b).

We can also compute firm i's relative long-run average inefficiencies using the resulting GMM estimates. The parameters $\beta_{0}$ and the $u_{i}^{L R}$ cannot be identified from these estimates without further restrictions, although $\delta_{i}^{\mathrm{LR}}=\beta_{0}-u_{\mathrm{i}}^{\mathrm{LR}}$ can be identified for each firm. However, following Schmidt and Sickles (1984), we can estimate the relative size of $u_{i}^{\mathrm{LR}}$ by $\left(\delta_{\max }^{\mathrm{LR}}-\hat{\delta}_{\mathrm{i}}^{\mathrm{LR}}\right)$, where $\delta_{\max }^{\mathrm{LR}}=\max _{\mathrm{j}}\left\{\hat{\delta}_{\mathrm{j}}^{\mathrm{LR}}\right\}$.

Model (7) or (9) can be more efficiently estimated under the deterministic frontier assumption. Note that under this assumption the regressor matrix $Z_{\mathrm{i}}$ in (9) is weakly exogenous with respect to the error vector $\mathrm{e}_{\mathrm{i}}$. Accordingly, we can consistently estimate $\theta$ by a nonlinear GLS (NLGLS) which iteratively solves the following problem:

$$
\min _{\theta} \sum_{\mathrm{i}=1}^{\mathrm{N}} \frac{1}{\hat{\sigma}_{\mathrm{i}}^{2}}\left(\mathrm{y}_{\mathrm{i}}-\mathrm{Z}_{\mathrm{i}} \pi(\theta)\right)^{\prime}\left(\mathrm{y}_{\mathrm{i}}-\mathrm{Z}_{\mathrm{i}} \pi(\theta)\right)
$$

In the first stage, $\hat{\sigma}_{i}^{2}=1$ for all $i$. Based on the resulting $\hat{\theta}$, we compute $\hat{\sigma}_{i}^{2}$ for the second stage. This procedure is repeated until $\hat{\theta}$ converges.

\footnotetext{
${ }^{6}$ We fix bandwidth at one to compute the Newey and West estimator of $\Omega_{\mathrm{i}}$, since the errors $\mathrm{e}_{\mathrm{it}}$ are MA(1) under our stochastic frontier assumption.
} 
Consistency and asymptotic efficiency of the NLGLS estimator requires the following moment conditions:

$$
\mathrm{E}\left(\mathrm{Z}_{\mathrm{i}}^{*^{\prime}} \mathrm{e}_{\mathrm{i}}^{*}\right)=0
$$

where $\mathrm{Z}_{\mathrm{i}}^{*}=\mathrm{Z}_{\mathrm{i}} / \sigma_{\mathrm{i}}$ and $\mathrm{e}_{\mathrm{i}}{ }^{*}=\mathrm{e}_{\mathrm{i}} / \sigma_{\mathrm{i}}$. Thus, the deterministic frontier assumption can be checked by testing these moment conditions. A Hansen test (1982) can be used to test for the conditions. Although this test requires computation of a GMM estimator optimal under given moment conditions, it can be easily shown that the NLGLS estimator, say $\hat{\theta}_{\mathrm{NLGLS}}$, is asymptotically identical to the optimal GMM estimator. Thus, an appropriate Hansen statistic for testing the moment conditions in (13) can be constructed by substituting $\hat{\theta}_{\mathrm{NLGLS}}$ for the optimal estimator. This replacement leads to the statistic

$$
\left[\sum_{i=1}^{N} Z_{i}^{*^{\prime}} \hat{\mathrm{e}}_{i}^{*}\right]^{\prime}\left[\sum_{i=1}^{\mathrm{N}} \mathrm{Z}_{\mathrm{i}}^{*^{\prime}} \mathrm{Z}_{\mathrm{i}}^{*}\right]^{+}\left[\sum_{\mathrm{i}=1}^{\mathrm{N}} \mathrm{Z}_{\mathrm{i}}^{*^{\prime}} \hat{\mathrm{e}}_{\mathrm{i}}^{*}\right],
$$

where $\hat{\mathrm{e}}_{\mathrm{i}}^{*}=\hat{\mathrm{e}}_{\mathrm{i}} / \sigma_{\mathrm{i}}$ and $\hat{\mathrm{e}}_{\mathrm{I}}$ is the GLS residual vector for firm i. This statistic is asymptotically $\chi^{2}$ with degrees of freedom equal to the rank of $\Sigma_{\mathrm{i}} \mathrm{Z}_{\mathrm{i}}{ }^{*} \mathrm{Z}_{\mathrm{i}}{ }^{*}$ minus the number of parameters in $\theta$.

An alternative specification method is also available. The main difference between the deterministic and stochastic frontier assumptions is that in (7), $\mathrm{y}_{\mathrm{i}, \mathrm{t}-1}$ is weakly exogenous under the former assumption, but not under latter. Thus, we can test for the former assumption against the latter focusing on the moment condition that $\mathrm{E}\left(\mathrm{e}_{\mathrm{it}} \mathrm{y}_{\mathrm{i}, \mathrm{t}-1}\right)=0$ for all $\mathrm{i}^{7}$ The conditional moment $(\mathrm{CM})$ test method developed by Newey (1985a) and Tauchen (1985) can be used to test for the hypothesis that this condition holds for any firm. In particular, using the method, we can easily obtain

\footnotetext{
${ }^{7}$ The J-test (14) can be used to test for weak exogeneity of $\mathrm{y}_{\mathrm{i}, \mathrm{t}-1}$, since the variable is included in $\mathrm{Z}_{\mathrm{i}}$. However, rejection of the model by the test does not necessarily mean that $y_{i t,-1}$ is correlated with $e_{i t}$ and the stochastic frontier is a better specification, since the rejection may be due to other possible sources of misspecification such as endogeneity of input variables.
} 
an appropriate statistic from an auxiliary regression. To be specific, let $\mathrm{R}_{\mathrm{u}}{ }^{2}$ be the uncentered $\mathrm{R}^{2}$ from the regression of the model

$$
\hat{\mathrm{e}}_{\mathrm{it}}^{*}=\mathrm{Z}_{\mathrm{it}}^{*} \Pi\left(\hat{\theta}_{\mathrm{NLGLS}}\right) \psi_{1}+\left(\mathrm{d}_{\mathrm{i}} \otimes \mathrm{y}_{\mathrm{i}, \mathrm{t}-1}^{*}\right) \psi_{2}+\mathrm{err},
$$

where $\mathrm{y}_{\mathrm{it}-1}^{*}=\mathrm{y}_{\mathrm{i}, \mathrm{t}-1} / \sigma_{\mathrm{i}}$ and $\Pi(\theta)=\partial \pi / \theta^{\prime}$. Then, a CM test statistic is computed by $\left(\Sigma_{\mathrm{i}} \mathrm{T}_{\mathrm{i}}\right) \mathrm{R}_{\mathrm{u}}{ }^{2}$, which is asymptotically $\chi^{2}$ with degrees of freedom equal to $\mathrm{N}{ }^{8}$

\section{Data}

We apply our production frontier model for the U.S. domestic airlines following deregulation of the industry. Other profit- and cost-based studies of the U. S. airline industry include, e.g. Sickles (1985), Sickles, Good and Johnson (1986), Kumbhakar (1992), Atkinson and Cornwell (1994), Baltagi, Griffin and Daniel (1995), and Good, Nadiri and Sickles (1997). Absolute and relative technical efficiencies as well as adjustment speeds are based on within, NLGLS, and GMM estimators. We use quarterly data (DOT-Form 41) from 1981-I to 1992-II (46 quarters) with a set consisting of 11 airlines with subscripts described by their two letter ticket codes: American (AA), Continental (CO), Delta (DL), Eastern (EA), Frontier (FL), Ozark (OZ), Piedmont (PI), Trans World (TW), United (UA), USAir (US) and Western (WA).

Our choice to begin the study in 1981 stems from the gradual way in which deregulation was implemented. Initially, deregulation gave airlines some downward flexibility in fares. Route entry and exit was very limited. Airlines could choose only one new unrestricted route per year. Since control over route structure is probably a more important mechanism for changing productive efficiency than is fare

\footnotetext{
${ }^{8}$ An alternative CM statistic can be obtained if we replace $\left(\mathrm{d}_{\mathrm{i}} \otimes \mathrm{y}_{\mathrm{it}-1}^{*}\right)$ in $(17)$ by $\mathrm{y}_{\mathrm{it}-1}^{*}$. Which of this and the CM test (15) may have better power is unknown, although the former test may be desirable for the analysis of data with large $\mathrm{N}$ and a short time series. In our empirical study detailed in section 4, we used both of the CM tests, but there was no difference in test results.
} 
flexibility, we chose the 1981, a point at which airlines were beginning to get entry/exit flexibility as the beginning of our study.

Because of the way in which Civil Aeronautics Board regulation was implemented in the 1970's the Air Deregulation Act of 1978 caused fundamental structural changes in the industry. $\mathrm{CAB}$ regulation promoted primarily the stability and financial viability of the industry. This meant that firms were not penalized for inefficiencies. For example, the $\mathrm{CAB}$ mandated that firms maintain inefficient route structures and service to small cities even though it was not profitable. Firms were either compensated explicitly through subsidy or implicitly through new route awards for these inefficiencies. Interpreted in the context of our model, the regulated era during which time there was little incentive to remove inefficiencies values of the $\rho_{\mathrm{i}}$ near 0 would be plausible and this is what we found in earlier analyses using data beginning in 1970 . The 1978 deregulation of the airline industry changed the emphasis in the industry to efficiency and competitiveness. This clearly suggests a structural change in our key parameters, the $\rho_{\mathrm{i}}$ which are found to differ substantially from 0 . The implications of $\rho_{\mathrm{i}}=0$ are not fully developed in our model. However, we point to the institutional sensibility of our post deregulatory results, along with the importance of the questions that are addressable by such a structural shift, in illustrating the usefulness of our model.

The data set is unbalanced panel with a total of 404 observations. The unbalanced nature of the panel raises the issue of selectivity, in particular that observations were systematically excluded from the study when firm performance was poor, stemming from high levels of inefficiency. Institutional evidence suggests that this was not the major reason for exit. First, most of the airlines exiting the sample were the result of mergers: USAir/Piedmont, TransWorld/Ozark, Delta/Western Frontier/People's Express. Only Braniff and Eastern Airlines left the industry as a result of failure. Braniff effectively failed at the start of the sample and, with only 2 usable observations, was left out of the study. Eastern's failure occurred rather late in the sample and lead to the loss of only two years of data. We chose to eliminate several 
firms from the study because they merged quickly after deregulation and were not in our panel long enough to provide useful estimates of their error structures. When firms merged, we kept the dominant firm (typically the largest) in the sample. Mergers may initially lead to an inefficiency shock to the decision making of the acquiring firm as it is left with a potentially inefficient combination of resources to serve their new route structure. However, a major advantage of our model is that it can accommodate such shocks as well as their gradual elimination. Further, the primary motivation behind the 1986 and 1987 flurry of mergers was the culmination of strategic alliances aimed at growing the route structure as quickly as possible through acquisition rather than expansion. These events occurred quickly because of the expectation that under the prevailing political climate the Department of Justice would not oppose such mergers. Finally, since nearly all of the airlines in the sample were involved in this type of merger activity, they are clearly representative of the industry. The unbalanced nature of the panel is not due to any major systematic selection rule. In cases where selectivity cannot be ruled out, Verbeek and Nijman (1992) provides statistical tests for these selection biases. The Hausman type test suggested by Verbeek and Nijman compares the technology estimates of the entire panel with the estimates from only the balanced portion of the panel. This yields a chi-square of 134.9 with $10 \mathrm{df}$ which is significant at any reasonable level. We discovered that the problem was one of data, in particular the last two quarters for Frontier Airlines which merged with People's Express and which presumably adopted the same shabby record keeping with the DOT as it was finalizing merger discussions as did People's Express during its entire operating life. If we delete the last two quarters for Frontier Airlines then the test yields a chi-square of 17.2 and is significant only at the $25 \%$ level. Deletion of these two observations from our analysis has only a marginal effect on our estimates and does not change our conclusions in any substantive way. We control for seasonal factors by including dummy variables for the first, second and third quarters of each year (QUA1, QUA2 and QUA3). Moreover, we include two quality variables: logarithm of stage length 
(SL) and percent wide body (PWB). The output measure is capacity-ton-mile and the inputs are labor (L), energy (E), materials $(\mathrm{M})$, capital (K). We use average stage length to control for heterogeneities in networks and percent of the fleet that is wide bodied aircraft to control for fleet heterogeneities. For a further discussion of the data construction see Sickles (1985) and Sickles, Good, Johnson (1986) and Alam and Sickles (2000).

For our empirical study, we estimate the Cobb-Douglas frontier instead of a more flexible functional form. We do so because interaction terms of input variables in our data are too highly correlated. ${ }^{9}$ Use of such variables would result in poorly estimated coefficients. In addition, as discussed later, our Hansen test results indicate little evidence against the Cobb-Douglas specification. Our Cobb-Douglas model also has the advantage that it imposes regularity on the production technology which might be violated with some technological specifications like the translog.

\section{Results}

We begin by estimating the frontier model (6) using the fixed effects panel frontier estimator (Schmidt and Sickles, 1984) assuming that $\rho_{\mathrm{i}}=1$ for all i. The results are reported in Table $\mathrm{I}^{10}$ Panel A reports the estimation results for the frontier production function. Panel B provides relative long-run average inefficiency levels and the Wald statistic for testing the hypothesis that firms' inefficiency levels fluctuate around a common level in the long run.

\footnotetext{
${ }^{9}$ Cornwell, Schmidt and Sickles (1990) find the same problem for the airline data covering the earlier time period.

${ }^{10}$ The reported results differ from the within estimation results reported in Cornwell, Schmidt, and Sickles (1990) as well as Schmidt and Sickles (1984), because the sample period of our data do not overlap with the data used in the two studies and we use different airlines. An interesting difference between our and their within results is that we obtain an insignificantly estimated time trend. An plausible explanation is that the productivity growth in airline industry was much higher during the 70 's than during 80's when the adoption of jet technology has been long completed.
} 
TABLE I

Within Estimation Results

\begin{tabular}{cccc|cccc}
\hline \hline \multicolumn{7}{c}{ A. Results for the frontier production function } \\
\hline Variable & Coefficient & Std. Err. & T-Stat. & Variable & Coefficient & Std. Err. & T-Stat \\
\hline $\ln (\mathrm{L})$ & -0.090 & 0.024 & -3.791 & QUA1 & -0.019 & 0.009 & -2.093 \\
$\ln (\mathrm{E})$ & 0.884 & 0.039 & 22.80 & QUA2 & 0.003 & 0.009 & 0.283 \\
$\ln (\mathrm{M})$ & 0.044 & 0.029 & 1.494 & QUA3 & 0.003 & 0.009 & 0.281 \\
$\ln (\mathrm{K})$ & 0.191 & 0.038 & 5.045 & TREND & 0.001 & 0.001 & 0.896 \\
$\ln (\mathrm{SL})$ & 0.227 & 0.041 & 5.464 & & & & \\
$\mathrm{PWB}$ & 0.621 & 0.125 & 4.980 & RTS & 1.028 & 0.012 & 83.109 \\
\hline $\mathrm{R}^{2}$ & 0.996 & & Obs. & & 404 & \\
\hline \hline
\end{tabular}

B. Relative Long-Run (LR) Inefficiency: The base firm is Frontier Airlines (FL)

\begin{tabular}{cccc|cccc}
\hline Airline & Estimate & Std. Err. & T-Stat. & Airline & Estimate & Std. Err. & T-Stat. \\
\hline FL & 0.000 & --- & --- & CO & 0.170 & 0.035 & 4.838 \\
WA & 0.037 & 0.033 & 1.107 & EA & 0.197 & 0.037 & 5.354 \\
PI & 0.044 & 0.024 & 1.878 & AA & 0.218 & 0.047 & 4.617 \\
OZ & 0.094 & 0.019 & 4.948 & UA & 0.220 & 0.048 & 4.602 \\
US & 0.112 & 0.022 & 5.057 & TW & 0.252 & 0.052 & 4.811 \\
DL & 0.134 & 0.039 & 3.440 & & & & \\
\hline \multicolumn{7}{l}{ Wald test for equality of LR effects $(\mathrm{df}=10)$} & \multicolumn{5}{c}{$117.42(\mathrm{p}=0.000)$} \\
\hline \hline
\end{tabular}

\section{Specification Test}

Significance test for lagged values of inputs ${ }^{* *} \quad 13.961$

$(\mathrm{df}=4) \quad(\mathrm{p}=0.007)$

"RTS means "returns to scale" obtained adding the coefficients of $\ln (\mathrm{L}), \ln (\mathrm{E}), \ln (\mathrm{M})$ and $\ln (\mathrm{K})$.

*** The test is for the exogeneity of lagged $\ln (L), \ln (E), \ln (M)$ and $\operatorname{in}(K)$ (with bandwidth $=4$ ).

The test result implies that this hypothesis should be rejected at any conventional significance level. Panel C reports the Wald test for the significance of lagged values of our four inputs (L, E, M and K). The robust covariance matrix used for this statistic is obtained by the Newey-West method as introduced in section $3 .{ }^{11}$ The test reveals evidence that the lagged values have power to explain the current output level. As discussed in section 1, this result is consistent with our assumption that

\footnotetext{
${ }^{11}$ For this test, we fix the bandwidth parameter for Newey-West estimators at four. Other values are also used, but the test result remains unaffected.
} 
firms' inefficiencies are autocorrelated.

TABLE II

Unit Root Test Results

\begin{tabular}{|c|c|c|c|c|}
\hline \multicolumn{5}{|c|}{ Tests with Linear Trend } \\
\hline & \multicolumn{2}{|c|}{$\mathrm{AR}(4)$} & \multicolumn{2}{|c|}{$\operatorname{AR}(6)$} \\
\hline Variables & Fisher Ststistic & P-Value & Fisher Ststistic & P-Vaue \\
\hline $\ln (Q)$ & 24.7248 & 0.3104 & 37.1778 & 0.0226 \\
\hline $\ln (\mathrm{L})$ & 62.5673 & 0.0000 & 54.1031 & 0.0002 \\
\hline $\ln (E)$ & 27.5069 & 0.1926 & 32.4132 & 0.0706 \\
\hline $\ln (\mathrm{M})$ & 37.1864 & 0.0226 & 39.1454 & 0.0136 \\
\hline $\ln (\mathrm{K})$ & 18.1891 & 0.6947 & 37.4512 & 0.0211 \\
\hline $\ln (\mathrm{SL})$ & 28.8376 & 0.1496 & 32.8678 & 0.0638 \\
\hline \multicolumn{5}{|c|}{ Tests with Quadratic Trend } \\
\hline & \multicolumn{2}{|c|}{$\mathrm{AR}(4)$} & \multicolumn{2}{|c|}{$\operatorname{AR}(6)$} \\
\hline Variables & Fisher Ststistic & P-Value & Fisher Ststistic & P-Vaue \\
\hline $\ln (\mathrm{Q})$ & 31.2144 & 0.0918 & 54.7346 & 0.0001 \\
\hline $\ln (\mathrm{L})$ & 54.1917 & 0.0002 & 42.0130 & 0.0062 \\
\hline $\ln (\mathrm{E})$ & 21.0260 & 0.5191 & 48.8326 & 0.0008 \\
\hline $\ln (\mathrm{M})$ & 29.1447 & 0.1408 & 26.0506 & 0.2495 \\
\hline $\ln (\mathrm{K})$ & 39.0939 & 0.0138 & 50.2484 & 0.0005 \\
\hline $\ln (\mathrm{SL})$ & 35.7730 & 0.0321 & 44.8364 & 0.0028 \\
\hline
\end{tabular}

We test for unit roots in the output and input variables using the Fisher-type statistics suggested by Maddala and Wu (1999) for our unbalanced panel. Using their method, we first estimate by OLS the model

$$
\ln \left(\mathrm{z}_{\mathrm{it}}\right)=\sum_{\mathrm{j}=1}^{\mathrm{p}} \zeta_{\mathrm{i}, \mathrm{j}} \ln \left(\mathrm{z}_{\mathrm{i}, \mathrm{t}-\mathrm{j}} / \mathrm{z}_{\mathrm{i}, \mathrm{t}-\mathrm{j}-1}\right)+\theta_{\mathrm{i}}+\gamma_{\mathrm{i}} \mathrm{t}+\delta_{\mathrm{i}} \ln \left(\mathrm{z}_{\mathrm{i}, \mathrm{t}-1}\right)+\varepsilon_{\mathrm{it}},
$$


where $z_{i t}$ is output or input levels. Then, for each $\mathrm{i}$, we compute the $\mathrm{t}$-statistic for the hypothesis that $\delta_{\mathrm{i}}=0$, which is simply the Augmented Dicky-Fuller (ADF) statistic. Let $\pi_{\mathrm{i}}$ be the $\mathrm{p}$-value for this ADF statistic for the i'th airline firm. Then, the Fisher statistic is given by $-2 \Sigma_{\mathrm{i}} \ln \left(\pi_{\mathrm{i}}\right)$. This statistic is asymptotically $\chi^{2}$-distributed with degrees of freedom equal to $2 \mathrm{~N}$ under the unit-root assumption. Maddala and $\mathrm{Wu}$ use a Monte Carlo method to estimate the p-values $\pi_{\mathrm{i}}$

In our studies, the number of time series observations for each airline is generally small (between 22 and 46). In order to improve the finite sample properties of the Fisher test, we use a bootstrap method to estimate $\pi_{\mathrm{i}}$. Specifically, for each $\mathrm{i}$, we estimate $\zeta_{\mathrm{ij}}, \theta_{\mathrm{i}}$ and $\operatorname{var}\left(\varepsilon_{\mathrm{it}}\right)$ under the unit-root assumption; that is, we estimate the model

$$
\ln \left(\mathrm{z}_{\mathrm{it}} / \mathrm{z}_{\mathrm{i}, \mathrm{t}-1}\right)=\sum_{\mathrm{j}=1}^{\mathrm{p}} \zeta_{\mathrm{i}, \mathrm{j}} \ln \left(\mathrm{z}_{\mathrm{i}, \mathrm{t}-\mathrm{j}} / \mathrm{z}_{\mathrm{i}, \mathrm{t}-\mathrm{j}-1}\right)+\theta_{\mathrm{i}}+\varepsilon_{\mathrm{it}} .
$$

Then, using these estimates and real values of $\mathrm{z}_{\mathrm{i} 1}, \mathrm{z}_{\mathrm{i} 2}, \ldots, \mathrm{z}_{\mathrm{i}, \mathrm{p}+2}$, we generate the series $\left\{z_{\mathrm{it}}\right\}$ assuming the $\varepsilon_{\mathrm{it}}$ are iid normal. We generate 10,000 different bootstrap data sets and compute the bootstrap ADF statistics for individual bootstrap data. From the empirical distribution of these bootstrap ADF statistics, we obtain the p-value $\pi_{\mathrm{i}}$. Our test results are found in Table II. We tested for unit-roots with $\mathrm{AR}(\mathrm{p})$ errors against the stationary model with AR.(p) and deterministic trend. For $\mathrm{p}=4$ and a linear trend, output, energy, capital and SL show evidence for unit roots. For $\mathrm{p}=6$ and linear trend, however, only energy and SL reveal only marginal evidence for unit roots. When we test for unit roots in these two variables, energy and SL allowing a quadratic trend under the alternative trend-stationary hypothesis, unit roots are no longer significant.

Table III reports the estimation results from NLGLS with restrictions $\rho_{\mathrm{i}}=\rho$ for all firms. The results reported in Panel A are quite different from those in Panel A of Table I. The coefficients of input variables are now all positively signed. These differences between results from Tables I and III would be explained by the results 
reported in Panel B of Table III. The estimated $\rho$ is significantly different from one,

TABLE III

\section{Restricted NLGLS Results for Deterministic Frontier $\left(\rho_{\mathrm{i}}=\rho\right.$ for all $\left.\mathrm{i}\right)$}

\begin{tabular}{|c|c|c|c|c|c|c|c|}
\hline \multicolumn{8}{|c|}{ A. Estimates for frontier production function } \\
\hline Variable & Coefficient & Std. Err. & T-Stat. & Variable & Coefficient & Std. Err. & T-Stat \\
\hline $\ln (\mathrm{L})$ & 0.025 & 0.012 & 2.059 & QUA1 & -0.004 & 0.002 & -2.220 \\
\hline $\ln (\mathrm{E})$ & 0.925 & 0.021 & 44.34 & QUA2 & 0.006 & 0.002 & 2.893 \\
\hline $\ln (\mathrm{M})$ & 0.0003 & 0.014 & 0.025 & QUA3 & 0.005 & 0.002 & 2.505 \\
\hline $\ln (\mathrm{K})$ & 0.033 & 0.093 & 3.600 & TIME & 0.002 & 0.001 & 3.357 \\
\hline $\ln (\mathrm{SL})$ & 0.220 & 0.049 & 4.534 & & & & \\
\hline PWB & 0.128 & 0.131 & 0.974 & RTS & 0.984 & 0.014 & 70.96 \\
\hline \multicolumn{8}{|c|}{ B. Estimation Results for Adjustment Speed } \\
\hline & Estimate & Std. Err. & T-Stat. & & & & \\
\hline$\rho$ & 0.177 & 0.025 & 6.983 & & & & \\
\hline
\end{tabular}

C. Output loss (\%) by sluggish adoption of technical innovations, (1-p) $\gamma / \rho$

\begin{tabular}{cccc|l}
\hline Airline & Estimate & Std. Err. & T-Stat. & \\
\hline 0.011 & 0.004 & 2.578 & \\
\hline \hline
\end{tabular}

D. Relative Long-Run (LR) Inefficiency: The base firm is Frontier Airlines (FL)

\begin{tabular}{cccc|cccc}
\hline Airline & Estimate & Std. Err. & T-Stat. & Airline & Estimate & Std. Err. & T-Stat. \\
\hline FL & 0.000 & --- & --- & OZ & 0.064 & 0.327 & 0.197 \\
WA & 0.015 & 0.327 & 0.046 & UA & 0.076 & 0.331 & 0.230 \\
PI & 0.033 & 0.327 & 0.099 & CO & 0.079 & 0.333 & 0.239 \\
DL & 0.039 & 0.329 & 0.118 & EA & 0.108 & 0.331 & 0.327 \\
US & 0.052 & 0.327 & 0.158 & TW & 0.127 & 0.333 & 0.380 \\
AA & 0.057 & 0.331 & 0.172 & & & & \\
\hline \multicolumn{7}{l}{ Wald test for equality of LR effects $(\mathrm{df}=10)$} \\
\hline \hline E. Specification Tests \\
\hline \multicolumn{7}{l}{ Hansen test (df=9) } \\
\hline
\end{tabular}

${ }^{*}$ The test is for exogeneity of one-period lagged output levels of all eleven firms.

suggesting that the fixed effects estimates reported in Table I are potentially biased ones. Panel B clearly indicates that firms' speed of adjusting their inefficiencies are considerably slow. If this tardy adjustment is due to firms' sluggish adoption of technical innovations in the airline industry, we can quantify the long-run output loss from sluggish adoption by $(1-\rho) \gamma / \rho$ (see equation (5) in section 2 ). We estimate this 
potential output loss and report the results in Panel C. The estimated output loss by sluggish adoption is only 1 percent of the frontier output level.

Panel D reports estimates of firms' relative long-run inefficiency levels. Ironically, the estimates indicate that the most efficient firm is Frontier Airlines, but the reported t-statistics show that other firms' inefficiencies compared to that of Frontier are statistically insignificant. Both the individual t-statistics and the reported Wald test statistic provide some evidence that airlines' inefficiency levels may be equalized in the long run. Furthermore, the dispersion of estimated relative inefficiencies is much narrower in Table 3. The productivity of the least efficient firm is $87.3 \%$ (1-0.127) of that of the most efficient firm in Table III and 74.8\% (10.252 ) in Table I. These results are in a great contrast to those obtained from the within estimation.

Panel E reports specification test results. The J-test (computed by (14)) does not reject the model specification at the 5\% significance level. However, the CM test (computed by (15)) shows some evidence against the model, indicating that lagged output levels may not be weakly exogenous. One possible source of this misspecification evidence is that speeds of adjusting inefficiency may differ across different firms. To check this possibility, we estimated the model allowing $\rho$ to vary across firms, but this was rejected by the J-test (see Table AI in the appendix). In general, our specification test results are not supportive of the deterministic frontier assumption.

The estimation results for the stochastic frontier are reported in Tables IV and V. For these tables, we use two sets of instruments. The first set includes 34 instruments, which are:

(IV 1) current values of logarithms of all input variables (L, E, M and K), the two quality variables (logarithm of SL, PWB), and the quarterly dummy variables (QUA1-3); one-period and two-period lagged values of logarithms of the four input variables and the two quality variables; firm dummy variables; 
(IV 2) time trend (TIME) and two-period lagged dependent variable. We denote GMM using these instruments by GMM1. The second set of instruments includes 54 variables. They are (IV 1) and cross-products of firm dummy variables and the instruments in (IV 2). We denote GMM using this set of instruments by GMM2. For large samples, more efficient estimators can be obtained by imposing more orthogonality conditions in GMM. However, recent studies show that in small samples, imposing more orthogonality conditions in GMM may result in more biases in estimates (Tauchen, 1986; and Hansen, Heaton and Yaron, 1996; and West and Wilcox, 1996), although using fewer orthogonality conditions is not always desirable, either (Anderson and Sørensen, 1996). Thus, our results for GMM2 should be interpreted with some caution. The reason for the two different GMM experiments is to see how sensitive estimation results are to the number of instrumental variables used.

Table IV reports the results from GMM1 with the restriction $\rho_{i}=\rho$ for all firms. The estimated frontier parameters reported in Panel A are qualitatively similar to those obtained from NLGLS, except that the time trend (and the estimated output loss reported in Panel C) is now unexpectedly insignificant. ${ }^{12}$ In Panel B, the estimated inefficiency adjustment speed $(\rho)$ is about 84 percent of the estimate from NLGLS, but it is still significantly different from zero. Similarly to those reported in Table 3, the individual t-statistics and the Wald statistic reported in Panel D fail to reject the hypothesis that all firms are equally inefficient in the long run at conventional levels. The J-test reported in Panel E indicates no strong evidence against the model specification and our choice of instruments. The value of the exogeneity test statistic (12.01) also indicates that exogeneity of two-period lagged output levels cannot be rejected at any conventional significance level. ${ }^{13}$

\footnotetext{
${ }^{12}$ We fixed the bandwidth at one for the Newey-West estimator. We used other values, but no significant changes in estimation results were observed.

${ }^{13}$ The null hypothesis we test is that for each firm, two-period lagged output level is weakly exogenous. Thus, the statistic has the degrees of freedom equal the number of firms.
} 


\section{TABLE IV}

\section{Restricted GMM1 Results for Stochastic Frontier $\left(\rho_{\mathrm{i}}=\rho\right.$ for all $\left.\mathrm{i}\right)$}

\begin{tabular}{|c|c|c|c|c|c|c|c|}
\hline \\
\hline \multicolumn{8}{|c|}{ 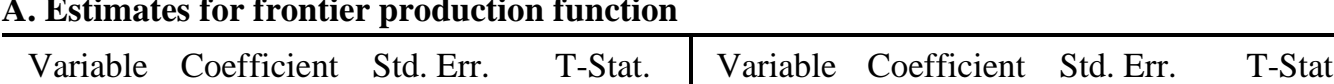 } \\
\hline $\ln (\mathrm{L})$ & 0.059 & 0.038 & 1.539 & QUA1 & -0.0005 & 0.004 & -0.107 \\
\hline $\ln (E)$ & 0.900 & 0.073 & 12.29 & QUA2 & 0.008 & 0.004 & 2.163 \\
\hline $\ln (\mathrm{M})$ & 0.015 & 0.031 & 0.490 & QUA3 & 0.007 & 0.003 & 2.172 \\
\hline $\ln (\mathrm{K})$ & 0.056 & 0.049 & 1.142 & TIME & 0.001 & 0.001 & 0.678 \\
\hline $\ln (\mathrm{SL})$ & 0.221 & 0.086 & 2.571 & & & & \\
\hline PWB & 0.122 & 0.160 & 0.762 & RTS & 1.030 & 0.032 & 32.48 \\
\hline
\end{tabular}

B. Estimation Results for Adjustment Speed

\begin{tabular}{cccc|l}
\hline & Estimate & Std. Err. & T-Stat. & \\
\hline$\rho$ & 0.149 & 0.050 & 2.997 & \\
\hline \hline
\end{tabular}

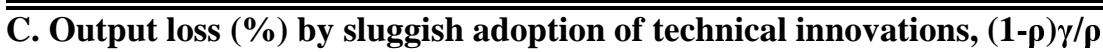

\begin{tabular}{|c|c|c|c|c|c|c|c|}
\hline Airline & Estimate & Std. Err. & T-Stat. & & & & \\
\hline & 0.006 & 0.009 & 0.615 & & & & \\
\hline \multicolumn{8}{|c|}{ D. Relative Long-Run (LR) Inefficiency：The base firm is Frontier Airlines (FL) } \\
\hline Airline & Estimate & Std. Err. & T-Stat. & Airline & Estimate & Std. Err. & T-Stat. \\
\hline FL & 0.000 & --- & --- & $\mathrm{CO}$ & 0.107 & 0.082 & 1.301 \\
\hline WA & 0.012 & 0.083 & 0.149 & TW & 0.137 & 0.103 & 1.331 \\
\hline $\mathrm{OZ}$ & 0.049 & 0.066 & 0.740 & AA & 0.139 & 0.097 & 1.438 \\
\hline PI & 0.059 & 0.076 & 0.777 & EA & 0.141 & 0.087 & 1.622 \\
\hline US & 0.085 & 0.081 & 1.050 & UA & 0.143 & 0.100 & 1.428 \\
\hline DL & 0.103 & 0.095 & 1.085 & & & & \\
\hline
\end{tabular}

Wald test for equality of LR effects $(\mathrm{df}=10)$

$11.88(\mathrm{p}=0.293)$

E. Specification Tests

\begin{tabular}{cc|cc}
\hline Hansen test $(\mathrm{df}=12)$ & $11.18(\mathrm{p}=0.513)$ & Exo. test $^{*}(\mathrm{df}=11)$ & $12.01(\mathrm{p}=0.363)$ \\
\hline \hline
\end{tabular}

${ }^{*}$ The test is for exogeneity of two-period lagged output levels of all eleven firms.

Table V reports the results from GMM2 with the restrictions $\rho_{\mathrm{i}}=\rho$ for all firms. The estimated frontier parameters and the adjustment speed are qualitatively similar to those reported in Table IV. As usual asymptotic theory suggests, GMM2 appears more efficient than GMM1 with the estimated standard errors of GMM2 estimates typically smaller than those of GMM1 estimates. The two specification tests again do not reject the stochastic frontier model specification. The most efficient firm is 
again Frontier Airlines.

\section{TABLE V}

\section{Restricted GMM2 Results for Stochastic Frontier $\left(\rho_{\mathrm{i}}=\rho\right.$ for any $\left.\mathrm{i}\right)$}

\begin{tabular}{|c|c|c|c|c|c|c|c|}
\hline \multicolumn{8}{|c|}{ A. Estimates for frontier production function } \\
\hline Variable & Coefficient & Std. Err. & T-Stat. & Variable & Coefficient & Std. Err. & T-Stat \\
\hline $\ln (\mathrm{L})$ & 0.059 & 0.023 & 2.611 & QUA1 & -0.002 & 0.003 & -0.657 \\
\hline $\ln (\mathrm{E})$ & 0.853 & 0.034 & 25.18 & QUA2 & 0.009 & 0.003 & 2.770 \\
\hline $\ln (\mathrm{M})$ & 0.031 & 0.020 & 1.580 & QUA3 & 0.006 & 0.003 & 2.436 \\
\hline $\ln (\mathrm{K})$ & 0.075 & 0.037 & 2.053 & TIME & 0.001 & 0.001 & 1.044 \\
\hline $\ln (\mathrm{SL})$ & 0.249 & 0.054 & 4.600 & & & & \\
\hline PWB & 0.258 & 0.131 & 1.962 & RTS & 1.018 & 0.020 & 50.26 \\
\hline \multicolumn{8}{|c|}{$\overline{\bar{B} \text { B. Estimation Results for Adjustment Speed }}$} \\
\hline & Estimate & Std. Err. & T-Stat. & & & & \\
\hline$\rho$ & 0.185 & 0.048 & 3.831 & & & & \\
\hline
\end{tabular}

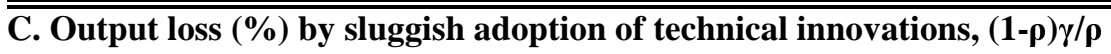

\begin{tabular}{cccc|l}
\hline Airline & Estimate & Std. Err. & T-Stat. & \\
\hline & 0.004 & 0.005 & 0.968 & \\
\hline \hline
\end{tabular}

D. Relative Long-Run (LR) Inefficiency: The base firm is Frontier Airlines (FL)

\begin{tabular}{cccc|cccc}
\hline Airline & Estimate & Std. Err. & T-Stat. & Airline & Estimate & Std. Err. & T-Stat. \\
\hline FL & 0.000 & --- & --- & AA & 0.187 & 0.080 & 2.334 \\
WA & 0.066 & 0.057 & 1.163 & CO & 0.190 & 0.065 & 2.896 \\
PI & 0.095 & 0.056 & 1.692 & EA & 0.196 & 0.065 & 3.014 \\
OZ & 0.107 & 0.051 & 2.115 & UA & 0.198 & 0.078 & 2.552 \\
US & 0.117 & 0.062 & 1.897 & TW & 0.211 & 0.079 & 2.680 \\
DL & 0.135 & 0.067 & 2.026 & & & & \\
\hline
\end{tabular}

Wald test for equality of LR effects $(\mathrm{df}=10)$

$31.73(\mathrm{p}=0.0004)$

\begin{tabular}{cc|cc}
\hline \hline E. Specification Tests & \multicolumn{3}{l}{} \\
\hline Hansen test $(\mathrm{df}=32)$ & $26.40(\mathrm{p}=0.745)$ & Exo. test $^{*}(\mathrm{df}=11)$ & $6.248(\mathrm{p}=0.856)$ \\
\hline \hline
\end{tabular}

${ }^{*}$ The test is for exogeneity of two-period lagged output levels of all eleven firms.

A notable difference however appears in Panel D. Both the individual $t$ tests and Wald test now reject the hypothesis of long-run equality among firms' technical inefficiencies. The estimated relative technical inefficiencies are quite similar to the within results reported in Table I instead of those reported in Table IV, although the dispersion of relative inefficiencies is slightly narrower in Table V than in Table I. 
Although Table V provides some evidence that long-run technical inefficiencies may differ across firms, some caution is required for proper statistical inferences based on GMM2. There are some reasons why the results in Panel D of Table V may be suspect. Observe that GMM2 generates considerably greater values of the estimated relative efficiencies than does GMM1. This result indicates a possibility of finite-sample biases in GMM2 caused by imposing too many moment conditions. To explore this possibility further, we conducted some unreported experiments. We found that the values of estimated relative inefficiencies tend to increase with the number of instruments used. These results are of course not sufficient to conclude that the statistical significance reported in Panel D is purely an outcome of finitesample biases caused by imposing too many moment conditions. ${ }^{14}$ However, the results clearly indicate that GMM using a large number of instruments tends to exaggerate the long-run divergence of technical inefficiencies. Furthermore, when we estimate the model allowing heterogeneity in the adjustment speed, the estimates of relative inefficiencies from GMM2 no longer appear to be statistically significant (see Table AII in the appendix).

\section{Conclusions}

We have studied a dynamic model that attempts to provide a more structural explanation for the variation in firm efficiency. Different from models of other previous studies (Schmidt and Sickles, 1984; Cornwell, Schmidt and Sickles, 1990; Kumbhakar, 1990; Battese and Coelli, 1992), our model assumes that technical inefficiency evolves autoregressively over time due to firms' inability to adjust their

\footnotetext{
${ }^{14}$ For an intermediate case between GMM1 and GMM2, we estimated the model by GMM using 44 instruments, which are (IV 1), time trend, and the cross products of firm dummy variables and twoperiod lagged dependent variables. The Wald statistic still rejected the hypothesis of equal long-run inefficiencies $(\mathrm{p}=0.0095)$. However, the dispersion of estimated long-run inefficiencies were quite close to those reported in Panel D of Table 4. For example, in this estimation the productivity of the least efficient firm was $85 \%$ (1-0.151) of that of the most efficient firm.
} 
productivity in a timely manner. Our model reduces to a usual dynamic panel data model if the speed of adjusting inefficiency can be assumed to be the same for all firms.

The choice of an appropriate estimation procedure for the model depends on whether the frontier function is deterministic or stochastic. We considered estimation of the model under each of these assumptions and suggested several specification tests. We also have applied our methodology to the U.S. airline industry and have found the stochastic frontier assumption to be appropriate for studies of that industry. Our estimation and test results are somewhat supportive of the hypothesis that the pattern of productivity adjustment is homogeneous across airlines. Whether technical inefficiency levels of firms in an industry tend to converge in the long run is an interesting empirical issue and recently has been explored in a different context by Alam and Sickles (2000). The results of our analysis for the airline industry do not indicate strong evidence against this hypothesis. Our empirical study shows that once short-run dynamics in technical inefficiencies are controlled, the cross-sectional dispersion of long-run inefficiencies shrinks toward the most efficient firm. It would be interesting to see whether this result can be generalized to other industries. Short-run dynamics in inefficiencies should be properly controlled to obtain proper statistical inferences regarding longrun inefficiencies. Our results indicate that fixed effects estimates obtained ignoring dynamics of technical inefficiency may exaggerate heteroskedasticity in long-run inefficiency. 


\section{ACKNOWLEDGMENTS}

The authors wish to thank Robert M. Adams for his valuable research assistance. Ahn gratefully acknowledges the financial support of the College of Business and Dean's Council of 100 at Arizona State University, the Economic Club of Phoenix, and the alumni of the College of Business. Good and Sickles acknowledge the valuable research support from the Logistics Management Institute and the National Aeronautics and Space Administration. The authors would like to thank participants in seminars at Rice University and Tulane University, the Seventh Biennial Panel Data Conference, Copenhagen, as well as Adrian Pagan, the referees, and the Editor for their useful suggestions and insights. We make the usual caveat.

\section{$\underline{\text { REFERENCES }}$}

Ahn, S. C. (1997), "Orthogonality tests in linear models," Oxford Bulletin of Economics \& Statistics 59, 183-186.

Ahn, S. C., Y. H. Lee and P. Schmidt (1995), "GMM estimation of a panel data regression model with time-varying individual effects," unpublished manuscript, Arizona State University.

Ahn, S. C., D. H. Good and R. C. Sickles (1997), "Estimation of long-run inefficiency levels: A dynamic Frontier approach," unpublished manuscript, Arizona State University.

Ahn, S. C. and P. Schmidt (1995), "Efficient estimation of models for dynamic panel data," Journal of Econometrics, 68, 5-27.

Ahn, S. C. and P. Schmidt (1997), "Efficient estimation of dynamic panel data models: Alternative assumptions and simplified estimation," Journal of Econometrics, 76, 309-321.

Alam, I. S., and R. C. Sickles (2000), "A time series analysis of deregulatory dynamics and technical efficiency: the case of the U.S. airline industry," International Economic Review, 41, 203-218.

Arellano, M. and S. R. Bond (1991), "Some tests of specification for panel data: Monte Carlo evidence and an application to employment equations," Review of Economic Studies, 58, 277-297. 
Atkinson, S. E. and C. Cornwell (1994) "Parametric measurement of technical and allocative inefficiency with panel data," International Economic Review, 35, 231244.

Baltagi, B. H., J. M. Griffin and R. P. Daniel (1995), "Airline deregulation: the cost pieces of the puzzle," International Economic Review, 36, 245-259.

Battese, G. E. and T. J. Coelli (1992), "Frontier production functions, technical efficiency and panel data: with application to paddy farmers in India," Journal of Productivity Analysis, 3, 153-169.

Cornwell, C., P. Schmidt and R. C. Sickles (1990), "Production frontiers with cross-sectional and time-series variation in efficiency levels," Journal of Econometrics, 46, 185-200.

Good, D. H., M. I. Nadiri and R. C. Sickles (1997), "Index Number and Factor Demand Approaches to the Estimation of Productivity," Chapter 1 of the Handbook of Applied Econometrics, Volume II-Microeconometrics, M. H. Pesaran and P. Schmidt (eds.), Basil Blackwell: Oxford, 14-80.

Hansen, L. P. (1982), "Large sample properties of generalized method of moments estimators," Econometrica, 50, 1029-1054.

Hansen, L. P., J. Heaton and A. Yaron (1996), "Finite-sample properties of some alternative GMM estimators," Journal of Business and Economic Statistics, 14, 262-280.

Hamilton, J. (1994), Time Series Analysis (Princeton University Press, Princeton, NJ).

Kumbhakar, S. C. (1987), "Production frontiers and panel data: an application to U.S. class 1 railroads," Journal of Business and Economics Statistics, 5, 249-255.

Kumbhakar, S. C. (1990), "Production frontiers, panel data, and time-varying technical inefficiency," Journal of Econometrics, 46, 201-212.

Kumbhakar, S. C. (1992), "Allocative distortions, technical progress, and input demand in U. S. airlines: 1970-1984," International Economic Review, 33, 723737.

Lee, Y. H. and P. Schmidt (1993), "A production frontier model with flexible temporal variation in technical efficiency," Chapter 8, in The Measurement of Productive Efficiency Techniques and Applications, eds., Fried, H., C.A.K. 
Lovell, and S. Schmidt, Oxford Academic Press, 237-255.

Maddala, G. S., and S. Wu (1999), "A comparative study of unit root tests with panel data and a new simple test," Oxford Bulletin of Economics and Statistics, Special Issue, 631-652.

Newey, W. K. (1985a), "Maximum likelihood specification testing and conditional moment tests," Econometrica, 53, 1047-1070.

Newey, W. K. (1985b), "Generalized method of moments specification testing," Journal of Econometrics, 29, 229 - 256.

Newey, W. K. and K. D. West (1987), "Hypothesis testing with efficient method of moments estimation," International Economic Review, 28, 777 - 787.

Schmidt, P. (1984), "Frontier production function," Econometric Reviews, 4, 289 328.

Schmidt, P. and R.C. Sickles (1984), "Production frontiers and panel data," Journal of Business and Economic Statistics, 2, 367-374.

Sickles R. C. (1985), “A nonlinear multivariate error-components analysis of technology and specific factor productivity growth with an application to the $\mathrm{U}$. S. airline industry," Journal of Econometrics, 27, 61-78.

Sickles, R. C., D. Good and R. Johnson (1986) "Allocative distortions and the regulatory transition of the U.S. airline industry," Journal of Econometrics, 33, $143-163$.

Tauchen, G. (1985), "Diagnostic testing and evaluation of maximum likelihood models," Journal of Econometrics, 30, 415-443.

Tauchen, G. (1986), "Statistical properties of generalized method-of-moments estimators of structural parameters obtained from financial market data," Journal of Business and Economic Statistics, 4, 397-416.

Verbeek, M. and T. Nijman (1992), "Incomplete panels and selection bias," Chapter 13 in The Econometrics of Panel Data: Handbook of Theory and Applications, eds., L. Mátyás and P. Sevestre, Kruwer Academic Publishers, 262-302.

West, K. D. and D. W. Wilcox (1996), "A comparison of alternative instrumental variables estimators of a dynamic linear model," Journal of Business and Economic Statistics, 14, 281-293. 
Zellner, A., J. Kmenta and J. Drèze (1966), "Specification and estimation of CobbDouglas production function models," Econometrica, 34, 784-795. 


\section{$\underline{\text { APPENDIX }}$}

TABLE AI

\section{Unrestricted NLGLS Results for Deterministic Frontier}

\begin{tabular}{|c|c|c|c|c|c|c|c|}
\hline \multicolumn{8}{|c|}{ A. Estimates for frontier production function } \\
\hline Variable & Coefficient & Std. Err. & T-Stat. & Variable & Coefficient & Std. Err. & T-Stat \\
\hline $\ln (\mathrm{L})$ & 0.014 & 0.012 & 1.223 & QUA1 & -0.004 & 0.002 & -2.181 \\
\hline $\ln (\mathrm{E})$ & 0.956 & 0.018 & 53.92 & QUA2 & 0.005 & 0.002 & 2.575 \\
\hline $\ln (\mathrm{M})$ & -0.008 & 0.013 & -0.614 & QUA3 & 0.004 & 0.002 & 1.929 \\
\hline $\ln (\mathrm{K})$ & 0.034 & 0.010 & 3.413 & TIME & 0.002 & 0.001 & 3.120 \\
\hline $\ln (\mathrm{SL})$ & 0.236 & 0.046 & 5.127 & & & & \\
\hline PWB & 0.170 & 0.114 & 1.490 & RTS & 0.995 & 0.010 & 96.34 \\
\hline \multicolumn{8}{|c|}{$\overline{\text { B. Estimation Results for Adjustment Speed }}$} \\
\hline & Estimate & Std. Err. & T-Stat. & & Estimate & Std. Err. & T-Stat \\
\hline$\rho_{\mathrm{AA}}$ & 0.159 & 0.039 & 4.061 & $\rho_{\mathrm{PI}}$ & 0.179 & 0.124 & 1.441 \\
\hline$\rho_{\mathrm{CO}}$ & 0.529 & 0.130 & 4.072 & $\rho_{\mathrm{UA}}$ & 0.164 & 0.069 & 2.387 \\
\hline$\rho_{\mathrm{DL}}$ & 0.144 & 0.068 & 2.119 & $\rho_{\mathrm{US}}$ & 0.061 & 0.038 & 1.583 \\
\hline$\rho_{\mathrm{EA}}$ & 1.034 & 0.202 & 5.118 & $\rho_{\mathrm{TW}}$ & 0.472 & 0.130 & 3.635 \\
\hline$\rho_{\mathrm{FL}}$ & 1.046 & 0.219 & 4.786 & $\rho_{\mathrm{WA}}$ & 0.274 & 0.118 & 2.321 \\
\hline$\rho_{\mathrm{OZ}}$ & 0.484 & 0.112 & 4.332 & & & & \\
\hline \multicolumn{4}{|c|}{$\begin{array}{l}\text { Wald test for equality of adjustment speeds } \\
\qquad(\mathrm{df}=10)\end{array}$} & \multicolumn{4}{|c|}{$\begin{array}{c}65.875 \\
(\mathrm{p}=0.000) \\
\end{array}$} \\
\hline \multicolumn{8}{|c|}{ C. Relative Long-Run (LR) Inefficiency: The base firm is Frontier Airlines (FL) } \\
\hline Airline & Estimate & Std. Err. & T-Stat. & Airline & Estimate & Std. Err. & T-Stat. \\
\hline FL & 0.000 & --- & --- & AA & 0.088 & 0.223 & 0.395 \\
\hline US & 0.014 & 0.226 & 0.060 & $\mathrm{CO}$ & 0.110 & 0.255 & 0.432 \\
\hline PI & 0.032 & 0.255 & 0.127 & EA & 0.112 & 0.298 & 0.337 \\
\hline WA & 0.038 & 0.250 & 0.152 & UA & 0.112 & 0.230 & 0.487 \\
\hline DL & 0.065 & 0.231 & 0.284 & TW & 0.157 & 0.255 & 0.614 \\
\hline $\mathrm{OZ}$ & 0.077 & 0.248 & 0.312 & & & & \\
\hline \multicolumn{4}{|c|}{ Wald test for equality of LR effects $(\mathrm{df}=10)$} & \multicolumn{4}{|c|}{$2.477(\mathrm{p}=0.991)$} \\
\hline
\end{tabular}

D. Specification Tests

\begin{tabular}{ll|ll}
\hline Hansen test $(\mathrm{df}=106)$ & $150.66(\mathrm{p}=0.003)$ & $\mathrm{CM} \mathrm{test}^{*}(\mathrm{df}=11)$ & $8.698(\mathrm{p}=0.650)$ \\
\hline \hline
\end{tabular}

${ }^{*}$ The test is for exogeneity of one-period lagged output levels of all eleven firms. 
TABLE AII

Unrestricted GMM2 Results for Stochastic Frontier

\begin{tabular}{|c|c|c|c|c|c|c|c|}
\hline \multicolumn{8}{|c|}{ A. Estimates for frontier production function } \\
\hline Variable & Coefficient & Std. Err. & T-Stat. & Variable & Coefficient & Std. Err. & T-Stat \\
\hline $\ln (\mathrm{L})$ & 0.032 & 0.023 & 1.353 & QUA1 & -0.002 & 0.004 & -0.639 \\
\hline $\ln (\mathrm{E})$ & 0.914 & 0.062 & 14.64 & QUA2 & 0.007 & 0.003 & 1.922 \\
\hline $\ln (\mathrm{M})$ & 0.017 & 0.030 & 0.577 & QUA3 & 0.005 & 0.003 & 1.722 \\
\hline $\ln (\mathrm{K})$ & 0.064 & 0.051 & 1.253 & TIME & -0.0004 & 0.001 & -0.265 \\
\hline $\ln (\mathrm{SL})$ & 0.248 & 0.083 & 2.986 & & & & \\
\hline PWB & 0.087 & 0.155 & 0.558 & RTS & 1.027 & 0.030 & 34.12 \\
\hline \multicolumn{8}{|c|}{$\begin{array}{l}\text { B. Estimation Results for Adjustment Speed } \\
\end{array}$} \\
\hline & Estimate & Std. Err. & T-Stat. & & Estimate & Std. Err. & T-Stat \\
\hline$\rho_{\mathrm{AA}}$ & 0.092 & 0.040 & 2.316 & $\rho_{\mathrm{PI}}$ & 0.074 & 0.186 & 0.399 \\
\hline$\rho_{\mathrm{CO}}$ & 0.053 & 0.093 & 0.570 & $\rho_{\mathrm{UA}}$ & 0.090 & 0.112 & 0.802 \\
\hline$\rho_{\mathrm{DL}}$ & 0.064 & 0.137 & 0.468 & $\rho_{\mathrm{US}}$ & 0.044 & 0.042 & 1.031 \\
\hline$\rho_{\mathrm{EA}}$ & 0.030 & 0.213 & 0.142 & $\rho_{\mathrm{TWA}}$ & 0.307 & 0.158 & 1.950 \\
\hline$\rho_{\mathrm{FA}}$ & 0.891 & 0.220 & 4.048 & $\rho_{\mathrm{WA}}$ & 0.267 & 0.279 & 0.954 \\
\hline$\rho_{\mathrm{OZ}}$ & 0.233 & 0.149 & 1.568 & & & & \\
\hline \multicolumn{4}{|c|}{$\begin{array}{l}\text { Wald test for equality of adjustment speeds } \\
\qquad(\mathrm{df}=10)\end{array}$} & \multicolumn{4}{|c|}{$\begin{array}{c}18.84 \\
(\mathrm{p}=0.042) \\
\end{array}$} \\
\hline
\end{tabular}

C. Relative Long-Run (LR) Inefficiency: The base firm is Frontier Airlines (FL)

\begin{tabular}{cccc|cccc}
\hline Airline & Estimate & Std. Err. & T-Stat. & Airline & Estimate & Std. Err. & T-Stat. \\
\hline FL & 0.000 & --- & --- & EA & 0.107 & 0.258 & 0.413 \\
US & 0.017 & 0.223 & 0.075 & CO & 0.117 & 0.238 & 0.490 \\
WA & 0.059 & 0.363 & 0.163 & AA & 0.128 & 0.223 & 0.574 \\
DL & 0.074 & 0.247 & 0.301 & UA & 0.149 & 0.242 & 0.615 \\
PI & 0.083 & 0.276 & 0.300 & TW & 0.177 & 0.278 & 0.639 \\
OZ & 0.099 & 0.262 & 0.375 & & & & \\
\hline \multicolumn{7}{l}{ Wald test for equality of LR effects $(\mathrm{df}=10)$} \\
\hline \hline \\
\hline \multicolumn{7}{l}{ D. Specification Tests } \\
\hline \hline
\end{tabular}

${ }^{*}$ The test is for exogeneity of two-period lagged output levels of all eleven firms. 